\title{
Economic, Environmental, and Social Sustainability Assessment of Queensland Industries ${ }^{\dagger}$
}

\author{
Alisher Ergashev \\ Queensland Department of Agriculture and Fisheries, Brisbane 4000, Australia; \\ Alisher.Ergashev@daf.qld.gov.au \\ + Presented at the third International Tropical Agriculture Conference (TROPAG 2019), Brisbane, Australia, \\ 11-13 November 2019. \\ Published: 13 January 2020
}

\begin{abstract}
In 'Our Future State: Advancing Queensland's Priorities' the Queensland Government outlined how industries and government should contribute to community well-being. Agriculture's contribution lies in generating economic activity, job creation and the Great Barrier Reef protection. While lack of data prevents the measurement of some attributes in the government plan, composite sustainability indices have been used worldwide to represent the wider objectives of "triple bottom line" economics (growth and throughput), social justice (fair and equitable distribution of the wealth) and environment-friendliness (compatibility with the preservation of natural ecosystems). One such approach is an innovative self-designed iSENSE index-indicators of Sustainability: ENvironmental, Social, and Economic - that is based on 15 indicators with a maximum overall score of 30. The featured indicators are based on a literature review and represent commonly accepted parameters. In this study, iSENSE indicators have been enumerated for the analysis of three Queensland sectors: Agriculture, Mining, and Manufacturing. The results show that while Mining leads the group in terms of economic indicators, it is Agriculture that is the most socially oriented and environment-friendly. Overall, iSENSE score is equal 16 for both Agriculture and Mining, whilst Manufacturing stands at 13 . While these results should be taken with caution, they can be used as a guidance for prospective policy proposals in conjunction with the sound ex post impact assessments around Queensland industries. Applying composite assessment tools can help to identify challenges related to environmental, economic and social impact, in the course of developing sustainable agriculture.
\end{abstract}

Keywords: sustainability; agriculture; mining; manufacturing; Queensland

Funding: This research received no external funding.

Acknowledgments: The author wishes to acknowledge the assistance and valued insights of the colleagues from Industry Analysis, Queensland Department of Agriculture and Fisheries. In particular, the report was revised by Dr George Antony and supported by the work-experience student Rohan Reddy.

Conflicts of Interest: The author declares no conflict of interest.

(C) 2020 by the authors. Licensee MDPI, Basel, Switzerland. This article is an open access article distributed under the terms and conditions of the Creative Commons Attribution (CC BY) license (http://creativecommons.org/licenses/by/4.0/). 